\title{
Efficiency of post-stratification for a large-scale forest inventory-case Finnish NFI
}

\author{
Helena Haakana $^{1}$ (D) Juha Heikkinen ${ }^{2} \cdot$ Matti Katila $^{1} \cdot$ Annika Kangas $^{3}$ \\ Received: 13 February 2018 / Accepted: 26 December 2018 / Published online: 30 January 2019 \\ (C) The Author(s) 2019
}

\begin{abstract}
- Key message Post-stratification based on remotely sensed data is an efficient method in estimating regional-level results in the operational National Forest Inventory. It also enables calculating the results accurately for smaller areas than with the default method of using the field plots only.

- Context The utilization of auxiliary information in survey sampling through model-assisted estimation or post-stratification has gained popularity in forest inventory recently. However, post-stratification at a large scale involves practical concerns such as the availability of auxiliary data independent of the sample at hand, and a large number of variables for which the results are needed. - Aims We assessed the efficiency of two different types of post-stratification, either post-stratifying for each variable of interest separately or using one post-stratification for all variables, compared to the estimation based on the field sample plots only. In addition, we examined the precision of area and volume estimates, and the efficiency of post-stratification at different spatial scales.

- Methods For post-stratification, we used the volume maps based on Landsat satellite imagery, digital map data, and the sample plot data of the previous inventory. The efficiencies of post-stratifications based on the mean volume and the mean volumes by tree species were compared.

- Results In estimating the total volume, the relative efficiency of post-stratification compared to field plot based estimation was 1.54-3.54 over the provinces in South Finland. In estimating the volumes by tree species groups, the relative efficiency was $0.93-$ 2.39. The gain with a separate stratification compared to the stratification based on total mean volume for all variables was at largest 0.69 . In the small test areas, the relative standard errors of the total volume estimates decreased on average by $33 \%$ by using post-stratification instead of sample plots only. The mean relative efficiency was 2.36 .

- Conclusion The utilization of an old forest resources map and post-stratification based on the mean volume is an operational approach for the National Forest Inventory. Post-stratification also enables calculating the results accurately for markedly smaller areas than with the field plots only. Post-stratification reduced the probability of very high sampling variances, making the results more robust.
\end{abstract}

Keywords Forest resources map · Precision · Satellite images · Volume estimates

Handling Editor: Jean-Michel Leban

Helena Haakana

helena.haakana@luke.fi

1 Bioeconomy and Environment, Natural Resources Institute Finland (Luke), P.O. Box 2, 00790 Helsinki, Finland

2 Natural Resources, Natural Resources Institute Finland (Luke), P.O. Box 2, 00790 Helsinki, Finland

3 Bioeconomy and Environment, Natural Resources Institute Finland (Luke), P.O. Box 68, 80101 Joensuu, Finland

\section{Introduction}

The utilization of remotely sensed data as auxiliary information in forest inventory can markedly improve the precision of the estimates. One option for utilizing the auxiliary information is the model-assisted (MA) framework (Särndal et al. 1992). In MA estimation, while the model is used for improving the precision, the inference on the precision of the results is solely based on the design of the sample. Even if the model is incorrect, the results are not biased. Another option is the model-based (MB) approach, where the model is not only used for improving the precision, but the whole inference 
depends on it (Cassel et al. 1977). In the case of MB, an incorrect model will yield biased results. MB approach is often used for small-area estimation, but the problems in assessing the potential bias hinder the use of this method (Magnussen et al. 2016).

Another option for the utilization of auxiliary data is the poststratification (PS), where the sample is stratified after the data is collected (Holt and Smith 1979). PS can be considered to be a special case of MA, where a model with categorical explanatory variable(s) is utilized. Similar models could also be used in MB approach. All of these methods have gained popularity in forest inventory in recent years (e.g., McRoberts et al. 2002; Gregoire et al. 2011; Ståhl et al. 2011; McRoberts et al. 2012; Dahlke et al. 2013; Tipton et al. 2013; Saarela et al. 2015a, 2015b).

In many cases, PS is based on classifying the predictions of a model with continuous explanatory variables. MA with continuous independent variables is more efficient than MA with a low number of classes (i.e., PS), but with a reasonable number of strata (4 8 ) the two approaches are very close to each other with respect to precision (Myllymäki et al. 2017). This is reasonable as Myllymäki et al. (2017) carried out PS using the predictions from the same linear model that was also used in MA with continuous variables. With a high enough number of strata, PS can seem even more efficient than MA, but a large number of strata easily introduce other problems such as empty strata. McRoberts et al. (2017) used a $k$ nearest neighbor $(k \mathrm{nn})$ model in a comparison, and in their case study, MA with continuous variables produced $10-14 \%$ lower standard errors than PS for all considered numbers of strata (4 8). In PS, an empty stratum can be dealt with aggregating it into a larger stratum, which results in a less efficient PS than would have been expected without. However, if post-strata are based on a model, Cochran (1977, p. 133) indicates that there is little reduction in variance to be expected when more than six strata are used.

While the gains from either MA or PS are evident, the utilization of auxiliary information in a large-scale forest inventory is not necessarily straightforward in practice. One reason for this is that the number of variables of interest in forest inventory is usually very large (over 100 in the Finnish National Forest Inventory (NFI)), and modeling each variable of interest separately may be impractical (Opsomer et al. 2007). As the gains are dependent on the correlation between the variable of interest and the auxiliary variables, receiving full gains from the auxiliary information requires selecting the best combination of auxiliary variables separately for each variable of interest. It is possible to use PS based on a model estimated for one variable, say total volume or biomass, for all variables. However, that will introduce losses in efficiency. In MA approach, the use of one generic model form for all variables would be a feasible option but would also introduce losses in efficiency related to modeling each variable independently.

Another concern is the availability of an external model for MA or PS. If the model used in PS is constructed from the sample at hand (i.e., internal), it is called endogenous poststratification (Breidt and Opsomer 2008). Magnussen et al. (2015) and Kangas et al. (2016) showed in a simulation study that such an approach may lead to a serious underestimation of variances. On the other hand, a model available from a previous inventory can serve as an external model (Kangas et al. 2016; Myllymäki et al. 2017). Thus, for utilizing an external model in the current inventory, independent information derived from remote sensing or other auxiliary data sources at the time of the previous inventory need to be available, for estimating the external model and predicting a stratifying variable.

If it is not possible to get high-quality data as wall-to-wall auxiliary data, it is possible to utilize two-phase or three-phase approach. For instance, acquisition costs for wall-to-wall airborne laser scanning (ALS) data may be prohibitive, but strip data may be available. Then, the ALS strips can serve as a first phase sample, and MA or PS can be applied within the strips (Saarela et al. 2015b; Ene et al. 2018). In an operational NFI, wall-to-wall data is preferable for practical reasons, as results are calculated for areas with a high variety in size.

A third possibility would be to utilize the auxiliary information already at the design phase, in stratification (e.g., Katila and Tomppo 2002; Tomppo et al. 2014) or using a type of balanced sampling, e.g., a local pivotal method (Grafström et al. 2017; Räty et al. 2018). Katila and Tomppo (2002) used pre-stratification in the estimation of inventory results for small areas. The $k \mathrm{nn}$ estimation was employed by map strata, that is, all field plots within each map stratum were used for estimating the areas of land use classes and forest variables of the particular stratum. While pre- and post-stratification are closely related methods, pre-stratification may lead to unsatisfactory results for those variables that are not among the stratification criteria (Räty et al. 2018), and therefore, poststratification is more robust for a multi-purpose inventory such as NFI.

In some countries (e.g., Brazil, France, Netherland, Slovakia, Sweden, USA), auxiliary information is applied in NFI to improve efficiency (Tomppo et al. 2010). According to a questionnaire survey conducted by Barrett et al. (2016), such countries were $11 \%$ of the 45 respondents. Yet, in the Swedish NFI, official statistics are based solely on field plots, but small-area statistics are calculated by using design-based PS, where $k \mathrm{nn}$ maps or other map products are used for stratification (Fridman et al. 2014). In many other countries like Finland and Norway, the methodology is being developed, but the methods have not been introduced to operational use (McRoberts et al. 2012, 2014; Kangas et al. 2018).

In the current Finnish NFI, all national and regional level results (i.e., for provinces) are calculated based solely on field plots. Results for smaller areas, such as municipalities, that do not contain a sufficient number of plots for precise estimates have been calculated applying the multi-source NFI (MS-NFI) 
method which utilizes satellite images, digital map data and NFI field data (Tomppo et al. 2008). The estimates are weighted averages or sums of the field plot variables. The weights for the field plots are defined employing the $k \mathrm{nn}$ estimation method (Tomppo et al. 2008). However, the resulting estimates are then purely model-based, and field plots outside the target area are also used. This may introduce bias which is not estimable (see, however, Magnussen et al. 2014, 2016). Using PS in small-area estimation would enable design-based inference, rather than model-based inference (i.e., relying solely on the plots within the area for inference).

The aim of the current study was to assess the efficiency of PS estimation, compared to the field inventory, that is, estimation based on the sample plots only. First, we considered two different types of post-stratifications, either based on the predictions of the variable of interest, or the predictions for just one of the variables. We calculated the losses in efficiency due to not making separate post-stratification for all variables of interest. Secondly, we analyzed the effect of spatial scale on the efficiency of PS, given the current sampling design with a fixed number of clusters and sample plots per unit area. The aim was to explore what is the smallest size of a target area for which the NFI results could be calculated with an acceptable accuracy by using PS. In examining the results, the applicability of PS in the operational NFI was considered.

\section{Material and methods}

\subsection{Study areas and field data}

We used the sample plot data from the 11th NFI (NFI11) in Finland measured in 2009-2013. The study area covered 15 provinces in South Finland and included two sampling density regions (or geographical strata), where sampling designs were slightly different (Figs. 1 and 2) (Korhonen et al. 2017). The total area was $208,674 \mathrm{~km}^{2}$ of which $73 \%$ on land dominated by forests (Table 1). The most common tree species were Scots pine (Pinus sylvestris) and Norway spruce (Picea abies (L.) Karst.), and birches (Betula spp.) and other deciduous trees (mainly Populus tremula L. and Alnus spp.) had a lower proportion. The number of NFI11 sample plots in the study area was 63,706 , of which 46,914 were on land.

To estimate the effect of the size of an area on the precision of the results, we selected three test areas from both NFI sampling regions (Fig. 3). The areas were placed and delineated in a way that the number of clusters in each area was the same in both regions. The number of plots per clusters was fixed within each region but varied between the regions. The test areas were then divided into smaller areas so that the relation of the size and the number of clusters within the area remained constant (Fig. 2). The sizes of the smallest areas were $1 / 16$ of the largest, and they had 16 times less NFI clusters than the largest areas (Table 2). Spruce accounted for the highest percentage of volume in the test areas in sampling region 1 , whereas it was pine in sampling region 2 (Table 3).

\subsection{Field measurements}

The NFI11 field plots in the study areas were restricted angle count sample plots with a basal area factor (relascope factor) of 2.0 and a maximum radius of $12.52 \mathrm{~m}$. All trees on forested land were measured for their diameter at breast height $(d b h$, $1.3 \mathrm{~m}$ ), and every seventh tree was measured as a sample tree in more detail, for example, for height, age, and increment over the past 5 years (Korhonen et al. 2017). The stem volume of each sample tree was estimated by using volume functions (Laasasenaho 1982) based on $d b h$, tree height, and also the diameter at $6 \mathrm{~m}$ height if the tree was taller than $8 \mathrm{~m}$. For tally trees, the form height (stem volume per basal area) was estimated as a weighted mean of the form heights of the most similar sample trees (Korhonen et al. 2017). For the estimation of total and mean volumes by regions, tree stem volumes on sample plots were converted to volumes per hectare represented by each tree (Korhonen et al. 2017).

\subsection{Auxiliary information}

MS-NFI maps based on the sample plot data of the 10th NFI of Finland (NFI10) from the years 2005-2008 and Landsat 5 TM images from 2007 (Tomppo et al. 2012) were used as auxiliary data. The full-coverage raster maps with $20 \mathrm{~m}$ pixels were produced by combining satellite images, digital map data, and the NFI sample plot data, and by using the $k \mathrm{nn}$ method for estimating the volume of the growing stock $\left(\mathrm{m}^{3} /\right.$ ha) and the volumes by tree species groups (pine, spruce, birch, and other deciduous tree species) for each image pixel on the forestry land mask (Tomppo and Halme 2004; Tomppo et al. 2008). In the estimation, digital map data from the National Land Survey of Finland (NLS) was used to separate forestry land from other land use classes, such as agricultural land, roads, built-up areas, and waterbodies, i.e., to create a forestry land mask. Note, however, that the MS-NFI volume estimates were calculated for the pixels on the forestry land mask using all the sample plots classified as forestry land in the field independently of the map data value.

In post-stratification, we used the MS-NFI volume maps: the mean volume of the whole growing stock and the mean volumes of pine, spruce, birch, and other deciduous trees; and combinations of the other land-use classes from the NLS map data, in estimating results for the provinces. The same stratification based on the total mean volume was used in estimating the efficiency of PS in the areas of different sizes. Even though some of the plots were permanent, post-stratification was independent of NFI11 data in the sense that it did not use any NFI11 measurements. The dependence resulting from re- 


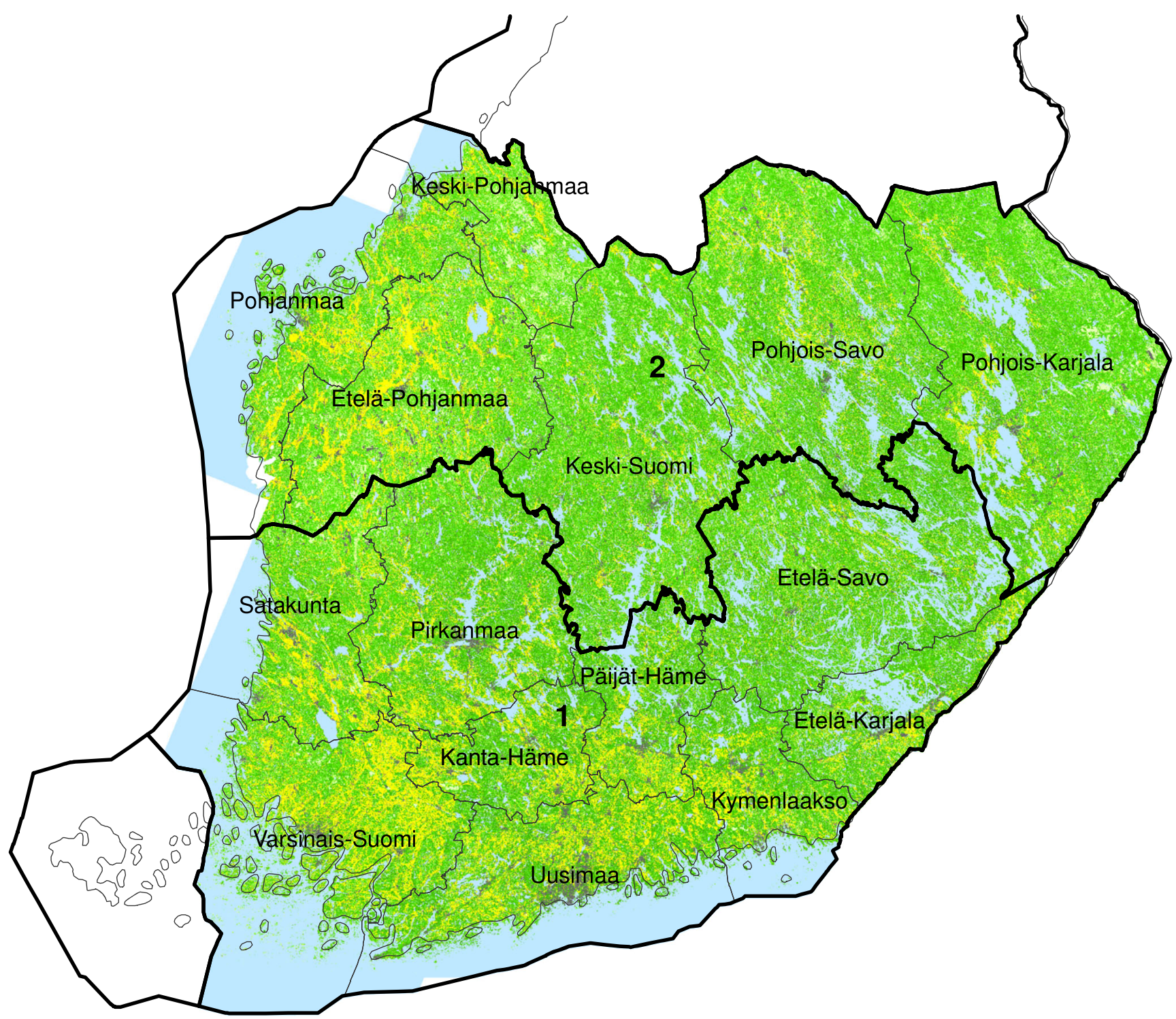

Fig. 1 The 15 provinces and the two sampling regions (with a thicker border line) on the raster map of the mean volume (MS-NFI 2007) over the study area in South Finland. On the map, yellow denotes agricultural

measured permanent plots does not introduce similar underestimation of variance as endogenous post-stratification (Kangas et al. 2016).

\subsection{Post-stratification}

For a single variable $y$, the best characteristic for the construction of strata would be the distribution of $y$ itself, or another variable $x$ highly correlated with it (Cochran 1977, p. 127). When remotely sensed data are used as auxiliary information, the number of potential explanatory variables is usually very high. Then, PS can be based, for instance, on the predictions $\hat{y}$ from a (linear or non-linear) model using some explanatory variables $x$ (e.g., Magnussen et al. 2015). land, blue water, gray built-up area, and green forestry land; the darker the shade, the higher the volume. Digital map data: National Land Survey of Finland 2012

Four volume strata were constructed with boundaries $y_{i}$, $i=0, \ldots, 4$, determined so that $y_{0}$ is the minimum and $y_{4}$ the maximum of predicted volumes $\hat{y}$, and the integrals $\int_{y_{0}}^{y_{i}} \sqrt{f(t)} d t, i=0, \ldots, 4$, are all equal, where $f$ is the probability density of the predictions (Dalenius and Hodges Jr 1959; Cochran 1977, p. 127, Sect. 5A.7). This approach produces an optimal (Neyman) allocation of plots to the used strata. Other options are available, for instance dividing the range of predictions or the cumulative distribution to equal size intervals (Myllymäki et al. 2017). In addition, because the forestry land mask is not reliable enough, other land use classes were stratified to three strata: agricultural land, built-up area, and waterbodies. In the MS-NFI volume maps 2007, there was a small area covered by clouds on the west coast (Fig. 1). The pixels under the cloud were stratified to the waterbodies as the sea covered most 


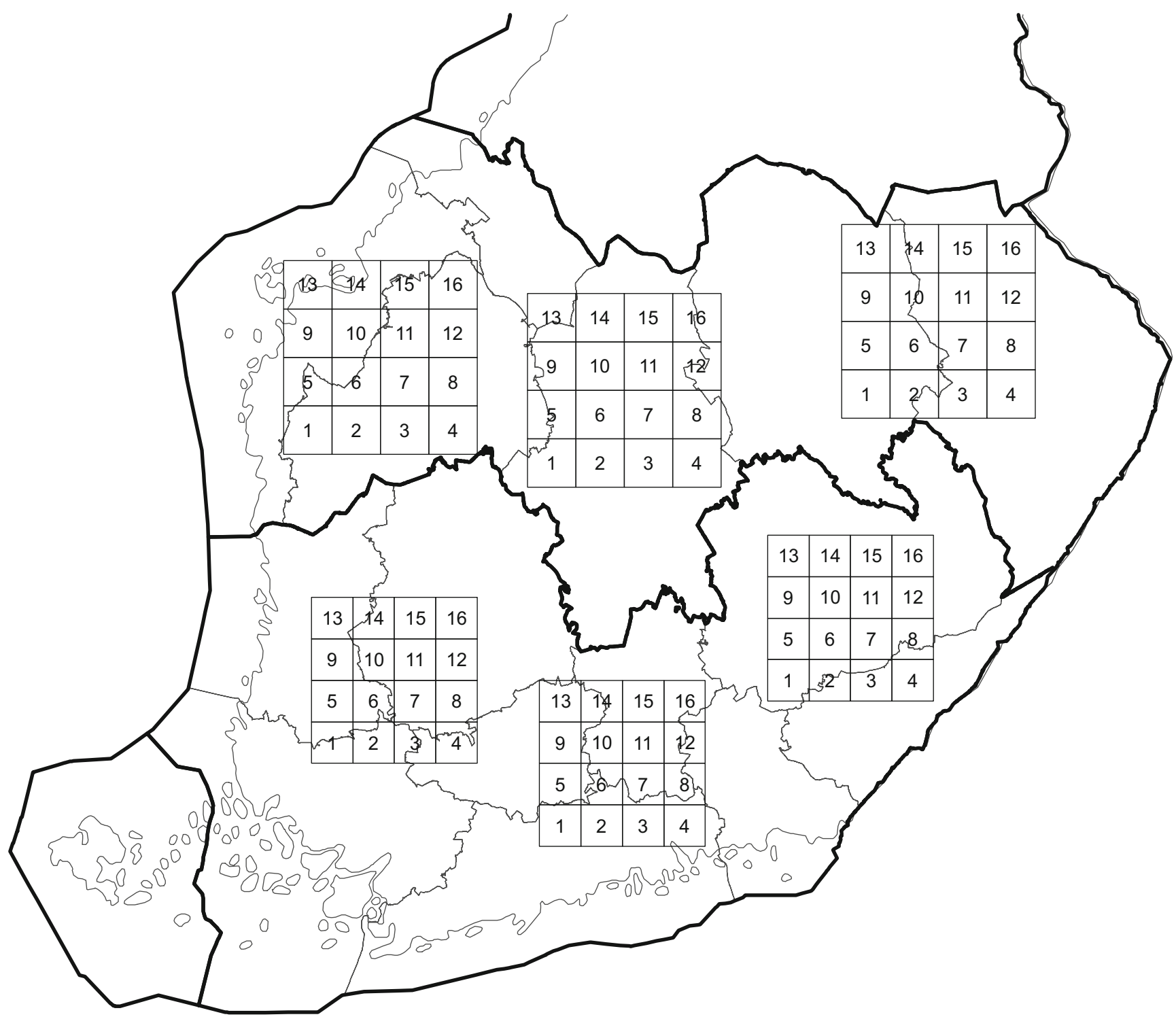

Fig. 2 The locations of the test areas of different sizes in sampling regions 1 (Southern Finland) and 2 (Central Finland)

of the area. The selection of four volume strata was based on previous experiences that little gain in precision was achieved with more than four to five Landsat-based strata (McRoberts et al. 2002; Nilsson et al. 2003; Katila 2006; McRoberts 2010; Magnussen et al. 2015).

\subsection{Post-stratified estimators and their sampling variance}

Forest areas were estimated by

$\hat{A}_{F}=\sum_{h=1}^{H} A_{h} \frac{n_{\mathrm{F}, h}}{n_{h}}$

where $A_{h}$ is the area of stratum $h$ based on the MS-NFI volume map, and $n_{h}$ is the total number of NFI plots and $n_{\mathrm{F}, h}$ the number of forest plots within that stratum, and total volumes by
$\hat{V}=\sum_{h=1}^{H} A_{h} \frac{u_{h}}{n_{\mathrm{F}, h}}$,

where $u_{h}=\sum_{k \in h} w_{k} f h_{k}$ is the weighted sum of estimated form heights (volume per basal area) of trees $k$ tallied in the plots of stratum $h$. In genuine relascope plots, weights $w_{k}$ would all be equal (i.e., basal area factor), but in plots with a maximum radius, large trees must be up-weighted; for further details, see Tomppo et al. (2011, Sect. 3.2.1).

The stratum-specific estimators of area proportions $\hat{a}_{h}=$ $n_{\mathrm{F}, h} / n_{h}$ (in Eq. 1) and mean volumes $\hat{v}_{h}=u_{h} / n_{\mathrm{F}, h}$ (in Eq. 2) are similar to ordinary NFI estimators, and their sampling variances were estimated as in the operational NFI, taking into account the clustering of sample plots and systematic sampling (Tomppo et al. 2011, Sect. 3.5.1). To be more precise, let us consider the generic form 
Table 1 Statistics of the estimates based on the NFI11 field inventory, and total and land areas based on the statistics of National Land Survey of Finland for the provinces

\begin{tabular}{lllll}
\hline Variable & Mean & Std dev & Min & Max \\
\hline Total area $\left(\mathrm{km}^{2}\right)$ & 13,912 & 6036 & 5708 & 21,584 \\
Land area $\left(\mathrm{km}^{2}\right)$ & 10,178 & 4745 & 5019 & 17,762 \\
Forested land area $\left(\mathrm{km}^{2}\right)$ & 7610 & 4306 & 3382 & 15,125 \\
Total volume $\left(1000 \mathrm{~m}^{3}\right)$ & 103,505 & 55,833 & 35,319 & 186,699 \\
Mean volume $\left(\mathrm{m}^{3} / \mathrm{ha}\right)$ & 138.7 & 19.1 & 98.5 & 163.1 \\
Proportion of pine $(\%)$ & 43.8 & 11.0 & 28.2 & 64.7 \\
Proportion of spruce $(\%)$ & 35.5 & 9.2 & 16.2 & 50.4 \\
Proportion of birch $(\%)$ & 16.1 & 2.0 & 12.7 & 19.5 \\
Proportion of other deciduous $(\%)$ & 4.6 & 1.7 & 2.0 & 8.5 \\
\hline
\end{tabular}

$\hat{\mu}_{h}=\frac{\sum_{c} y_{c, h}}{\sum_{c} x_{c, h}}$

of (stratum-specific) NFI estimators, where $y_{c, h}$ and $x_{c, h}$ are cluster-level plot counts or sums. For area proportions $\hat{a}_{h}$, $y_{c, h}$ is the number of forest plots and $x_{c, h}$ is the total number of plots in cluster $c$ that belong to stratum $h$. For mean volumes $\hat{v}_{h}, y_{c, h}$ is the weighted sum $u_{h}$ restricted to cluster $c$ and $x_{c, h}$ is the number of those forest plots of cluster $c$ that belong to stratum $h$. The sampling variance of $\hat{\mu}_{h}$ was estimated by

$\widehat{\operatorname{Var}}\left(\hat{\mu}_{h}\right)=\widehat{\operatorname{Var}}\left(\frac{\sum_{c} y_{c, h}}{\sum_{c} x_{c, h}}\right)=\frac{\sum_{g}\left(\sum_{c \in g} b_{c} z_{c, h}\right)^{2}}{\left(\sum_{c} x_{c, h}\right)^{2}}$,

where $z_{c, h}=y_{c, h}-\hat{\mu}_{h} x_{c, h}$ is a cluster-level residual, $g$ is a group of clusters close to each other, and the weights $b_{c}$ are determined so that each local quadratic form $\left(\sum_{c \in g} b_{c} z_{c}\right)^{2}$ is an unbiased estimator of the variance of $z_{c}$ 's (Matérn 1960, p. 110).

By analogy to Eq. 3, the mutual covariances of estimators $\hat{\mu}_{h}$ of area proportions or mean volumes were estimated by

$\widehat{\operatorname{Cov}}\left(\hat{\mu}_{h}, \hat{\mu}_{h^{\prime}}\right)=\frac{\sum_{g}\left(\sum_{c \in g} b_{c} z_{c, h}\right)\left(\sum_{c \in g} b_{c} z_{c, h^{\prime}}\right)}{\left(\sum_{c} x_{c, h}\right)\left(\sum_{c} x_{c, h^{\prime}}\right)}$,

where $x_{c, h}$ denotes the count or sum $x_{c}$ restricted to plots of stratum $h$. Finally, the sampling variances of post-stratified estimators $\hat{Y}=\sum_{h} A_{h} \hat{\mu}_{h}$ were estimated by

$\widehat{\operatorname{Var}}(\hat{Y})=\sum_{h} \sum_{h^{\prime}} A_{h} A_{h^{\prime}} \widehat{\operatorname{Cov}}\left(\hat{\mu}_{h}, \hat{\mu}_{h^{\prime}}\right)$

and the delta method was applied to approximate the variance of post-stratified estimators of mean volumes (Tomppo et al. 2011, Sect. 3.5.2):

$\widehat{\operatorname{Var}}(\hat{v})=\widehat{\operatorname{Var}}\left(\frac{\hat{V}}{\hat{A}}\right) \approx \hat{v}^{2}\left[\frac{\widehat{\operatorname{Var}}(\hat{V})}{\hat{V}^{2}}-\frac{\widehat{\operatorname{Var}}(\hat{A})}{\hat{A}^{2}}\right]$.
The relative efficiencies (RE) of post-stratified estimators $\hat{Y}_{\text {PS }}$ of forested area, total volumes $\left(\mathrm{m}^{3}\right)$, and volumes by tree species groups $\left(\mathrm{m}^{3}\right)$ compared to their ordinary NFI estimators $\hat{Y}_{\text {NFI }}$ based on the field data only were calculated as ratios of the estimated variances $\widehat{\operatorname{Var}}\left(\hat{Y}_{\mathrm{NFI}}\right) \widehat{\operatorname{Var}}\left(\hat{Y}_{\mathrm{PS}}\right)$. Relative standard error $\sqrt{\widehat{\operatorname{Var}}(\hat{Y})} / \hat{Y}$ was used as an absolute measure of sampling uncertainty. The estimation results are presented for "forested land," which consists of productive forest land (growth at least $1 \mathrm{~m}^{3} / \mathrm{ha} / \mathrm{a}$ ) and poorly productive forest land (growth at least $0.1 \mathrm{~m}^{3} / \mathrm{ha} / \mathrm{a}$ ) according to the national landuse classification and used in the NFI reporting. These national classes cover the global class of forest and, to a large extent, also other wooded land as defined by the Food and Agriculture Organization of the United Nations (FAO 2012).

\section{Results}

\subsection{Post-stratification}

A total of $58.9 \%$ of the sample plots in South Finland were in the volume strata (1-4) (Table 4) and the rest, $41.1 \%$, in the strata of other land use classes (5-7). The percentages of plots in agricultural land, built-up land, and waterbodies were $10.4 \%, 4.5 \%$, and $26.2 \%$, respectively, and the same in all stratifications.

In the test areas of different sizes, the distribution of sample plots to the strata differed between the sampling regions. The area of other land use and waterbodies, and consequently, the percentage of sample plots in the strata 5-7 were higher in Southern Finland (38.1\%) than in Central Finland $(29.2 \%)$. Moreover, the test areas differed in a way that in Southern Finland, the plot distribution to the volume strata was more even. The percentage of plots in the stratum of highest volume (202 $\mathrm{m}^{3} /$ ha and above) was $13.1 \%$, whereas in Central Finland, only $6.3 \%$.

\subsection{Comparison of field estimation and post-stratification at province level}

The use of PS based on the mean volume improved the precision of area and volume estimates clearly, compared to the NFI estimates based on the field inventory, i.e., sample plots only (Table 5). The mean relative efficiency in estimating forested land area was 3.26 in South Finland (Table 6) and at highest in the provinces of Uusimaa and Varsinais-Suomi, 4.64 and 4.47, respectively. In estimating the total volume, the mean relative efficiency of PS was 2.32 and at highest 3.54 in the province of Keski-Pohjanmaa (Fig. 4, Table 6).

Also for the volumes by trees species groups, PS based on the total mean volume was more efficient than the field 
Fig. 3 NFI sampling designs in sampling region 1 (Southern Finland, above) and 2 (Central Finland, below)
Table 2 Test areas and field data used in estimating the effect of size of the inventory area on the precision of results

\begin{tabular}{lllll}
\hline $\begin{array}{l}\text { Sampling } \\
\text { region }\end{array}$ & $\begin{array}{l}\text { Size of one } \\
\text { test area } \\
\left(\mathrm{km}^{2}\right)\end{array}$ & $\begin{array}{l}\text { Number } \\
\text { of test } \\
\text { areas }\end{array}$ & $\begin{array}{l}\text { Number of } \\
\text { clusters in one } \\
\text { test area }\end{array}$ & $\begin{array}{l}\text { Number of } \\
\text { sample plots in } \\
\text { one test area }\end{array}$ \\
\hline 1 & 576 & 48 & 20 & 184 \\
& 1152 & 24 & 40 & 368 \\
& 2304 & 12 & 80 & 736 \\
4608 & 6 & 160 & 1472 \\
& 9216 & 3 & 320 & 2944 \\
& 784 & 48 & 20 & 232 \\
& 1568 & 24 & 40 & 464 \\
& 3136 & 12 & 80 & 928 \\
6272 & 6 & 160 & 1856 \\
12,544 & 3 & 320 & 3712 \\
\hline
\end{tabular}
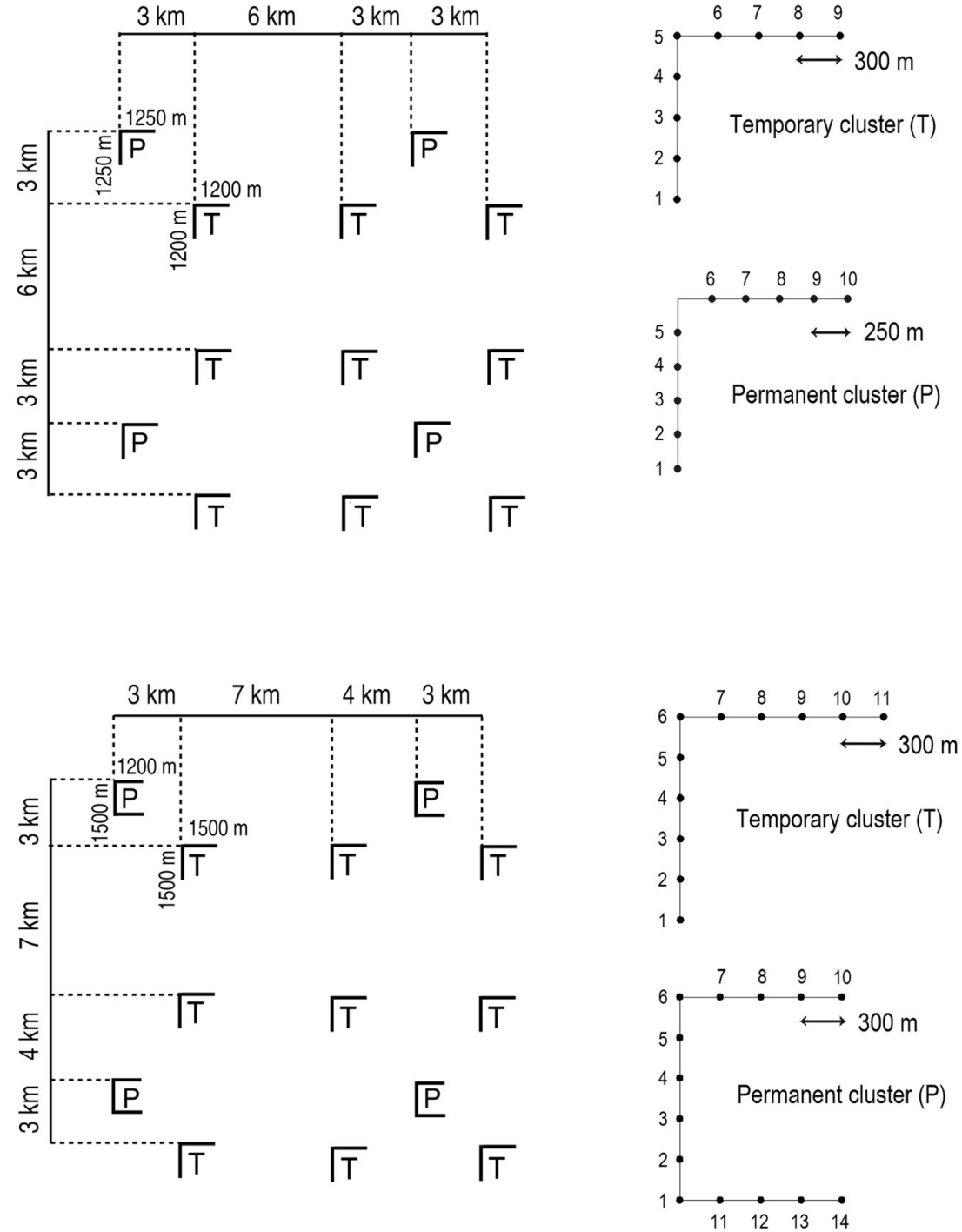

inventory, and slightly more if the mean volume of the tree species in question was used in the stratification (Table 6). PS based on the pine volume increased the efficiency at most by 0.58 in the province of PohjoisKarjala, compared to the PS based on the total mean volume (Fig. 5). The gain in the relative efficiency was on average 0.26 (Table 6). For spruce volume, the gain in efficiency by using PS based on the spruce volume compared to PS based on the mean volume was largest in the province of Keski-Pohjanmaa, 0.69 , and 0.28 on average (Fig. 6, Table 6). In estimating the total volume of birch, PS was slightly more efficient than the field inventory (1.14) in the whole South Finland, and PS based on the birch volume further improved the efficiency (1.34) (Fig. 4, Table 6). In estimating the volume of other deciduous tree species, PS and the field inventory were practically equally efficient in all provinces, and PS based on the mean volume of other deciduous trees hardly improved the efficiency (Fig. 4, Table 6). 
Table 3 Statistics of the estimates based on the NFI11 field inventory for the smallest test areas

\begin{tabular}{|c|c|c|c|c|c|c|}
\hline Sampling region & Size $\left(\mathrm{km}^{2}\right)$ & Variable & Mean & Std Dev & Min & Max \\
\hline \multirow[t]{8}{*}{1} & \multirow[t]{8}{*}{576} & Land area $\left(\mathrm{km}^{2}\right)$ & 488 & 80 & 212 & 573 \\
\hline & & Forested land area $\left(\mathrm{km}^{2}\right)$ & 337 & 57 & 188 & 482 \\
\hline & & Total volume $\left(1000 \mathrm{~m}^{3}\right)$ & 5196 & 1006 & 2226 & 7280 \\
\hline & & Mean volume $\left(\mathrm{m}^{3} / \mathrm{ha}\right)$ & 154.3 & 15.9 & 118.6 & 190.6 \\
\hline & & Proportion of pine (\%) & 35.5 & 14.1 & 11.3 & 76.3 \\
\hline & & Proportion of spruce (\%) & 42.7 & 12.7 & 5.0 & 59.7 \\
\hline & & Proportion of birch (\%) & 16.4 & 3.2 & 10.2 & 23.1 \\
\hline & & Proportion of other deciduous (\%) & 5.3 & 2.6 & 1.1 & 12.6 \\
\hline \multirow[t]{8}{*}{2} & \multirow[t]{8}{*}{784} & Land area $\left(\mathrm{km}^{2}\right)$ & 674 & 102 & 322 & 782 \\
\hline & & Forested land area $\left(\mathrm{km}^{2}\right)$ & 515 & 93 & 224 & 663 \\
\hline & & Total volume $\left(1000 \mathrm{~m}^{3}\right)$ & 6316 & 1296 & 3441 & 9090 \\
\hline & & Mean volume $\left(\mathrm{m}^{3} / \mathrm{ha}\right)$ & 123.4 & 18.0 & 90.6 & 167.9 \\
\hline & & Proportion of pine $(\%)$ & 51.5 & 12.9 & 14.8 & 76.8 \\
\hline & & Proportion of spruce (\%) & 29.1 & 10.2 & 9.9 & 54.4 \\
\hline & & Proportion of birch (\%) & 16.0 & 3.3 & 11.4 & 26.5 \\
\hline & & Proportion of other deciduous (\%) & 3.4 & 2.1 & 0.2 & 10.6 \\
\hline
\end{tabular}

\subsection{Effect of spatial scale on the precision}

In the test areas of different sizes, PS markedly improved the precision of area and volume estimates, compared to the field inventory. The mean relative standard error (SE) of the estimate for forested area decreased most in the smallest test areas, but the decrease was relatively highest in the largest test areas (Tables 7 and 8). For example, in the smallest areas $\left(576 \mathrm{~km}^{2}\right)$ in sampling region 1 , PS resulted in the mean SE $43 \%$ smaller than the mean SE with the field inventory, that is, the mean relative SE decreased from 7.81 to $4.43 \%$ (Table 7). In the largest areas $\left(9216 \mathrm{~km}^{2}\right)$, the mean SE was decreased by $50 \%$ by using PS. In estimating the total volume, PS improved the precision by $28 \%$ in the smallest and $35 \%$ in the largest areas (Fig. 7, Table 9). In the sampling region 2, the improvements were $29 \%$ and $37 \%$, respectively (Fig. 8, Table 10). With PS, the maximum values of SE were clearly lower than with the field inventory (Figs. 7 and 8). In general, PS was more efficient in all test areas. The mean REs for the forested area were in the range 3.12-3.86 (Tables 7 and 8) and for the total volume 2.09-2.52 (Tables 9 and 10). However, in some of the smallest test areas, the minimum RE values were below one, meaning that the field inventory occasionally produced more precise results than PS.

\section{Discussion}

The most important result from this study was that even though the mean volume was used for stratification, the results for the provinces were fairly good with all tested variables. In particular, it is important that no deterioration of efficiency was observed: Even if the improvement in RE was modest with some variables, the precisions still improved. The only exception was the volume of other deciduous trees, for which RE was below one in some of the provinces (Fig. 4). In an operational NFI, it is very important to get good estimates for all the variables in question. In connection with this study, we also tested PS for a large set of other variables, such as forested area and volumes by development classes (not reported here), and no significant deterioration of results was observed with any of the variables. One important variable, volume of dead wood was not included in our tests, but according to Nilsson et al. (2003, 2005), PS improved also the precision of dead-wood volume estimates compared to those based on NFI field data alone.

The relative efficiencies obtained in this study are consistent with the results of the previous studies on PS based on satellite imagery in forest inventories (Nilsson et al. 2003; Nilsson et al. 2005; McRoberts et al. 2006). The range of 1.54-3.53 in estimating the total volume over the provinces (Table 6) is similar to RE of 3.7 reported by Nilsson et al. (2003) and 1.1-1.7 by McRoberts et al. (2006). The lower REs in the North East states of USA were attributed to greater heterogeneity in forests there, characterized by naturally generated, mixed species and uneven-aged stands, than in Scandinavian countries (McRoberts et al. 2006). Nilsson et al. (2005) also concluded that stratification based on the stem volume of individual tree species did not improve the estimation precision of the variable in question, except the volume of deciduous trees. 
Table 4 Strata boundaries based on the MS-NFI volume maps and percentages of NFI11 sample plots in the volume strata in the estimation for the provinces

\begin{tabular}{llllll}
\hline Stratum & Volume $\left(\mathrm{m}^{3} / \mathrm{ha}\right)$ & Pine volume $\left(\mathrm{m}^{3} / \mathrm{ha}\right)$ & Spruce volume $\left(\mathrm{m}^{3} / \mathrm{ha}\right)$ & Birch volume $\left(\mathrm{m}^{3} / \mathrm{ha}\right)$ & Other deciduous volume $\left(\mathrm{m}^{3} / \mathrm{ha}\right)$ \\
\hline 1 & $<68$ & $<29$ & $<23$ & $<11$ & $<3$ \\
2 & $68-130$ & $29-66$ & $23-69$ & $11-27$ & $3-12$ \\
3 & $130-202$ & $66-109$ & $69-152$ & $27-53$ & $12-32$ \\
4 & $202 \leq$ & $109 \leq$ & $152 \leq$ & $53 \leq$ & $32 \leq$ \\
Stratum & Sample plots $(\%)$ & Sample plots $(\%)$ & Sample plots $(\%)$ & Sample plots $(\%)$ & Sample plots $(\%)$ \\
1 & 17.9 & 23.3 & 33.0 & 28.5 & 41.1 \\
2 & 17.5 & 15.2 & 13.9 & 16.1 & 11.3 \\
3 & 15.4 & 13.3 & 7.8 & 9.9 & 4.8 \\
4 & 8.1 & 7.0 & 4.1 & 4.5 & 1.7 \\
Total & 58.9 & 58.9 & 58.9 & 58.9 & 58.9 \\
\hline
\end{tabular}

In estimating forested land area, the efficiency of PS was highest in the provinces of Uusimaa and Varsinais-Suomi, where the percentage of other land use area is high (Table 6). In estimating the pine and spruce volumes, PS based on the mean volume of the species in question further improved the efficiency only by 0.27 on average (Table 6). In the case of pine volume, the highest gains were obtained in the provinces of Varsinais-Suomi, Pohjois-Karjala, and Etelä-Pohjanmaa (Fig. 5), where the percentage of pine of the total volume was also high. In the case of spruce, the gain was highest in the small province of Keski-Pohjanmaa (Fig. 6), which was, however, not related to the dominance of spruce in the area (only $16 \%$ of the total volume). One reason for the low improvement of efficiency by using PS based on the mean volumes by tree species is the poor precision of $k \mathrm{nn}$ predictions at the pixel level, about $60-80 \%$ for the mean volume and even over $100 \%$ for volumes by tree species (Katila and Tomppo 2001). In cross-validation tests by tree species groups, the proportion of the variation in the field plots explained by the $k \mathrm{nn}$ predictions was largest for the spruce volume, and for the volumes of deciduous tree species, the explanatory power was poor (Katila and Tomppo 2001). These findings seem to reflect to the gains in the precision using PS in this study. However, stratification at the pixel level may lead to the assigning of erroneous strata to the sample plots and confusing the estimation with PS based on the volumes by tree species. One solution to overcome the problem of large pixel-level variance in $k \mathrm{nn}$ predictions is segmentation of the volume maps or original Landsat images into homogenous units, and assigning each segment a stratum based on the mean volume within the segment in question (Nilsson et al. 2003, 2005). Also other postprocessing methods, such as edge preserving smoothing, could be used for reducing within stand variation on MS-NFI volume maps (Tomppo 1996). In the operational NFI, segmentation or filtering would bring an additional processing phase, but a possible improvement in efficiency due to better compatibility of strata and plot variables is worth exploring.
In Finland, the distribution of forest land and heterogeneity of forests differ from south to north due to climatic conditions. The current NFI sampling is adapted to this large-scale spatial variability and designed to produce reliable results for regional administrative units, sampling density regions following unit borders (Tomppo et al. 2011). One option would be to stratify the sampling regions separately, which was also tested in connection with this study. However, the same PS for the whole of South Finland was applied because it resulted in efficiencies very close to those obtained with the separate PSs for the sampling regions 1 and 2 . The separate PS improved the relative efficiency most, by 0.12 compared to PS for South Finland, in

Table 5 Statistics of relative estimation errors (SE) of variables of interest derived with the field inventory (NFI) and post-stratification based on different variables (PS) for the 15 provinces

\begin{tabular}{|c|c|c|c|c|}
\hline \multirow[t]{2}{*}{ Variable of interest } & \multirow[t]{2}{*}{ Method-stratification variable } & \multicolumn{3}{|c|}{$\mathrm{SE}(\%)$} \\
\hline & & Mean & Min & Max \\
\hline \multirow[t]{2}{*}{ Forested land area } & NFI & 1.93 & 0.68 & 3.23 \\
\hline & PS-mean volume & 1.05 & 0.52 & 2.06 \\
\hline \multirow[t]{2}{*}{ Total volume } & NFI & 2.75 & 1.44 & 4.36 \\
\hline & PS-mean volume & 1.78 & 1.08 & 2.78 \\
\hline \multirow[t]{3}{*}{ Pine volume } & NFI & 3.84 & 2.23 & 6.33 \\
\hline & PS-mean volume & 3.19 & 1.90 & 5.63 \\
\hline & PS-pine volume & 2.95 & 1.59 & 5.28 \\
\hline \multirow[t]{3}{*}{ Spruce volume } & NFI & 4.86 & 2.94 & 9.52 \\
\hline & PS-mean volume & 3.98 & 2.49 & 7.46 \\
\hline & PS-spruce volume & 3.62 & 2.36 & 6.18 \\
\hline \multirow[t]{3}{*}{ Birch volume } & NFI & 4.61 & 2.75 & 6.49 \\
\hline & PS-mean volume & 4.27 & 2.66 & 6.00 \\
\hline & PS-birch volume & 3.96 & 2.42 & 5.68 \\
\hline \multirow{3}{*}{$\begin{array}{l}\text { Volume of other } \\
\text { deciduous }\end{array}$} & NFI & 9.92 & 5.30 & 15.09 \\
\hline & PS-mean volume & 9.80 & 5.28 & 14.71 \\
\hline & PS-volume of other deciduous & 9.58 & 5.07 & 15.11 \\
\hline
\end{tabular}


Table 6 Statistics of relative efficiency (RE) of post-stratification based on different variables in estimation of variables of interest for the 15 provinces

\begin{tabular}{|c|c|c|c|c|}
\hline \multirow[t]{2}{*}{ Variable of interest } & \multirow[t]{2}{*}{ Stratification variable } & \multicolumn{3}{|l|}{$\mathrm{RE}$} \\
\hline & & Mean & Min & Max \\
\hline Forested land area & Mean volume & 3.26 & 1.70 & 4.64 \\
\hline Total volume & Mean volume & 2.32 & 1.54 & 3.54 \\
\hline \multirow[t]{2}{*}{ Pine volume } & Mean volume & 1.43 & 1.08 & 2.03 \\
\hline & Pine volume & 1.69 & 1.25 & 2.24 \\
\hline \multirow[t]{2}{*}{ Spruce volume } & Mean volume & 1.50 & 1.18 & 1.79 \\
\hline & Spruce volume & 1.79 & 1.54 & 2.39 \\
\hline \multirow[t]{2}{*}{ Birch volume } & Mean volume & 1.14 & 1.02 & 1.32 \\
\hline & Birch volume & 1.34 & 1.05 & 1.60 \\
\hline \multirow{2}{*}{$\begin{array}{l}\text { Volume of other } \\
\text { deciduous }\end{array}$} & Mean volume & 1.02 & 0.93 & 1.11 \\
\hline & Volume of other deciduous & 1.05 & 0.94 & 1.19 \\
\hline
\end{tabular}

estimating the total volume in the province of VarsinaisSuomi. This indicates that the regions also differ from west to east, or from coast to inland. PS of a smaller area could improve results in some divergent regions, but applying the same PS for the whole South Finland is more operational.

The efficiency of PS, for example, the mean value of 2.32 in estimating total volume (Table 6), can be interpreted so that the number of sample plots could be decreased by 2.32 to achieve the same precision as by the field inventory. If the precision of NFI results with the current sampling size is regarded to be sufficient, expensive field measurements could be reduced by using PS in calculating forest statistics for national and regional levels. On the other hand, as the efficiency for some variables, like the volume of other deciduous species did not improve, decreasing the number of plots would reduce the precision for those estimates. Thus, significant cost savings may not be achieved if the precision of these variables needs to be at the current level.

With PS, the current sampling can be used to estimate results for smaller areas than with the field inventory. The goal in developing the Finnish NFI is to provide forest information for smaller areas than provinces. The results for the test areas of different sizes showed that with PS, the total volume could be estimated with the relative SE lower than $5 \%$ for an area of $2304 \mathrm{~km}^{2}$ in Southern Finland and $1568 \mathrm{~km}^{2}$ in Central Finland, whereas with the field inventory for areas double the sizes of these. For the volumes by tree species groups, the relative SEs would be higher, for example, in the area of $2304 \mathrm{~km}^{2}$ in Southern Finland, and the average SEs were $7.9 \%$ for pine and $7.4 \%$ for spruce. It is notable that the small area estimates obtained with PS were robust, compared to the field plot based estimates, as the largest variances improved even more than the average variances.

PS with current field sampling is, however, not an adequate method to calculate results for all municipalities in South Finland, because their mean size is only $884 \mathrm{~km}^{2}$, ranging from the smallest urban municipality of $6 \mathrm{~km}^{2}$ to extensive rural municipalities at most of $5548 \mathrm{~km}^{2}$. Using PS, estimates of forest variables can be, however, obtained for large municipalities, combinations of municipalities, or different areas of interest other than administrative units. Thus, in the smallest municipalities, the model-based inference would still be needed. In a previous study, Katila (2006) reported that with MSNFI, that is, by means of $k \mathrm{nn}$, mean volume can be estimated
Fig. 4 Relative efficiencies (RE) of post-stratification in the estimation of the total volume of the growing stock and the volumes by tree species groups on forested land by the provinces in South Finland

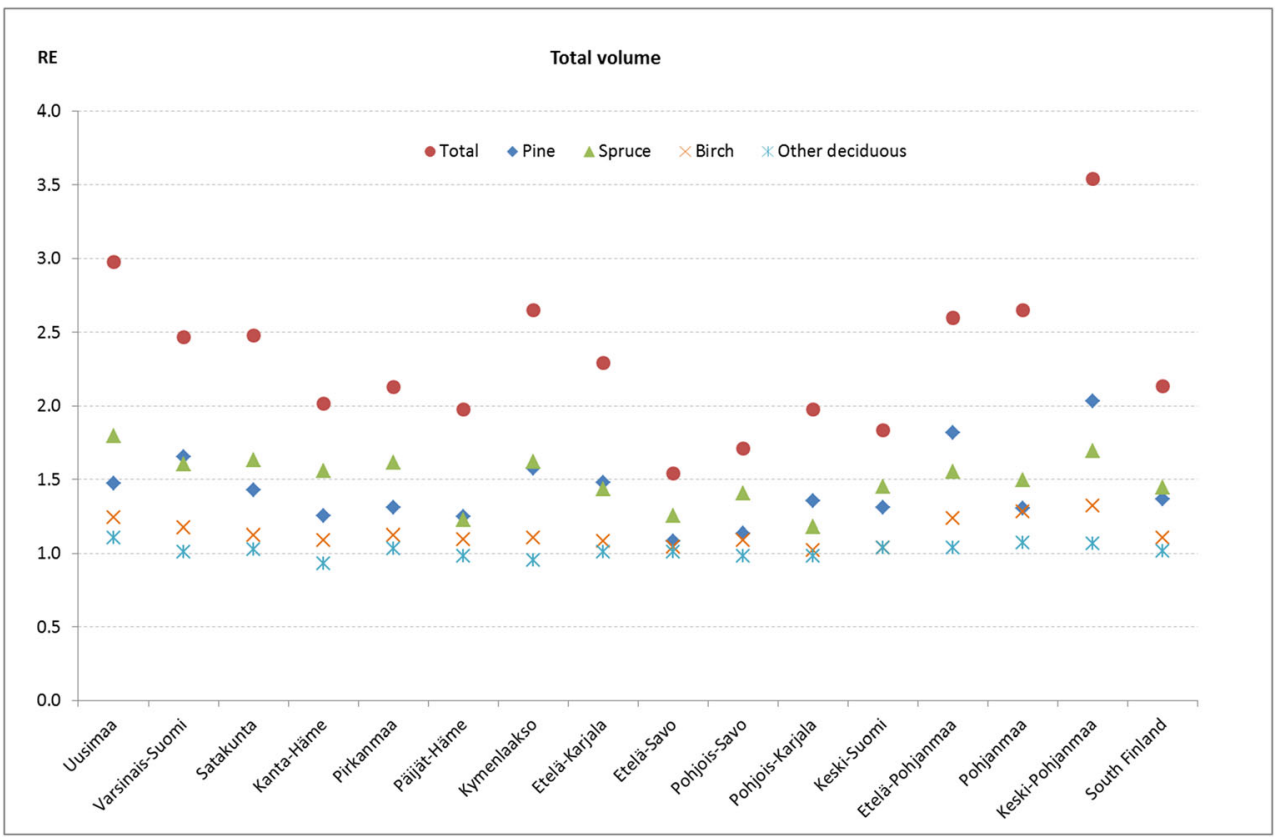


Fig. 5 Relative efficiencies (RE) of post-stratification based on the mean volume (PS) and the pine volume (PS-pine) in the estimation of the total pine volume on forested land by the provinces in South Finland

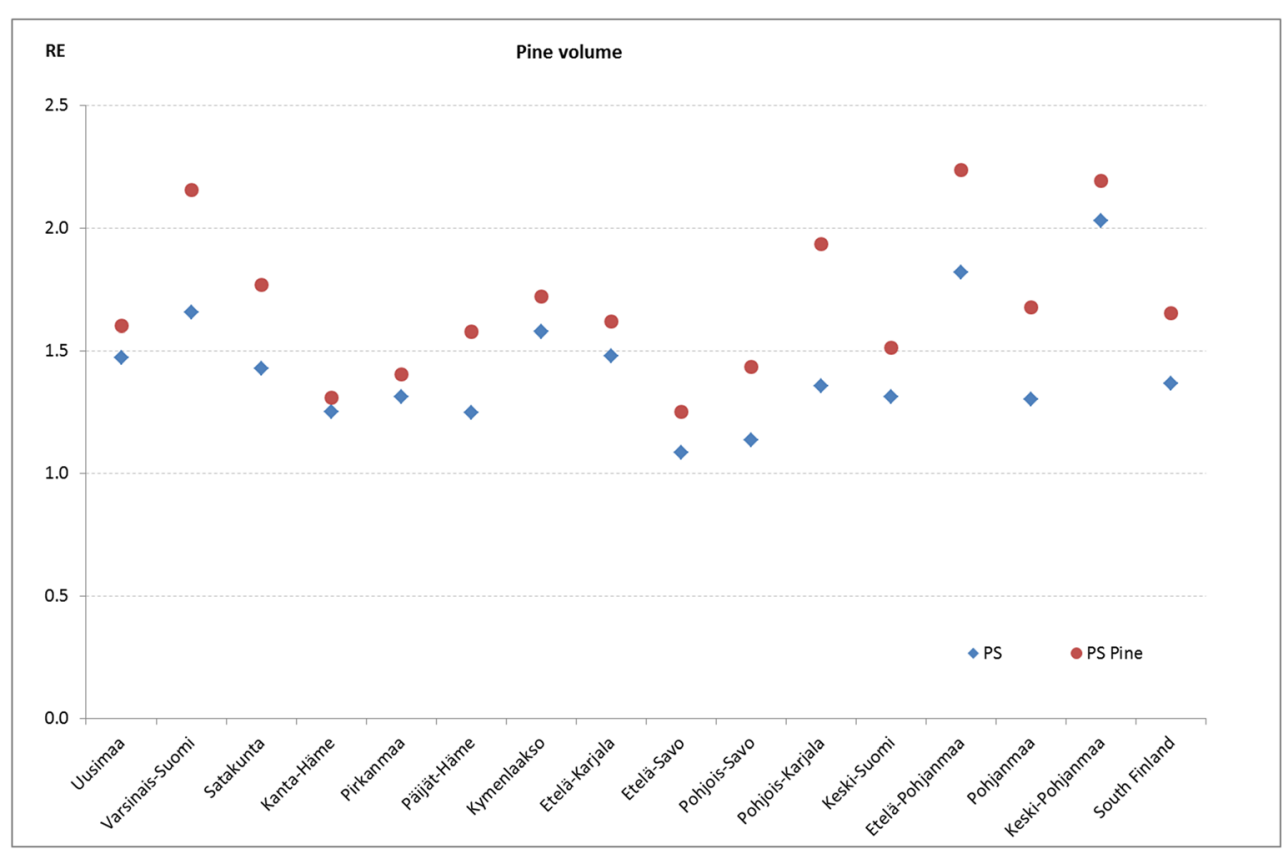

with a precision of $5 \%$ for areas of $100 \mathrm{~km}^{2}$ and larger. The problem with $k \mathrm{nn}$ is, however, the analytical inference. Estimators have been developed (e.g., Baffetta et al. 2009; Magnussen 2013), and in the future, these new estimators need to be tested in the operational NFI setting and compared to the well-established methods such as post-stratification to address their potential.

The improvements observed using PS were fairly good, given that the MS-NFI volume maps based on Landsat imagery several years older than the NFI11 data were used. The main reason for using the forest volume maps from an old inventory was to use independent auxiliary data and thus avoid the endogenous post-stratification. Compared to up-todate satellite images or laser scanning data, our approach is likely to produce a little less accurate results, i.e., the old data potentially reduces the efficiency. This is because between the two inventory rounds, large numbers of operations have been carried out in the forests, which reduce the correlation between the old MS-NFI map information and the current plot information. It is possible, however, to improve the results by updating the changes like clear-cut areas in the maps used for stratification. This can be done by using satellite images from
Fig. 6 Relative efficiencies (RE) of post-stratification based on the mean volume (PS) and the spruce volume (PS-Spruce) in the estimation of the total spruce volume on forested land by the provinces in South Finland

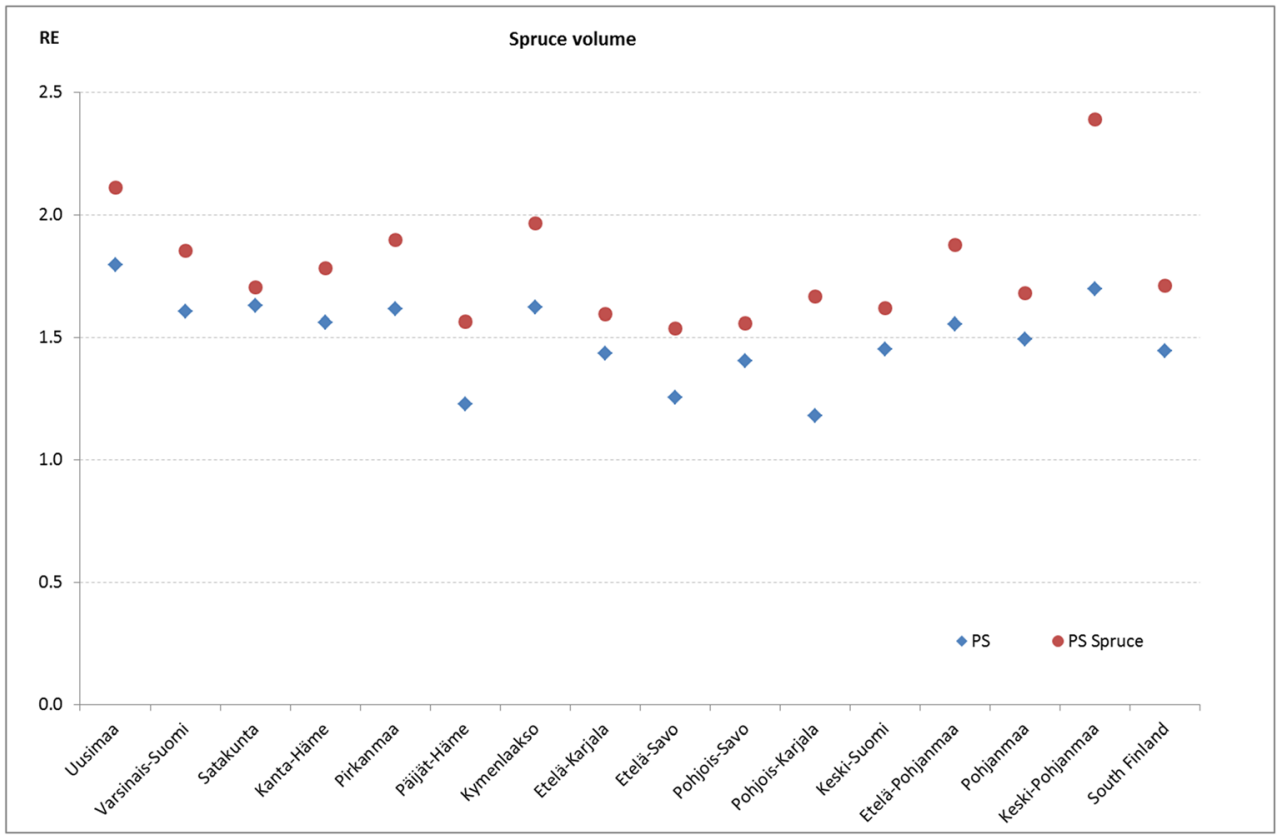


Table 7 Statistics of the relative estimation errors (SE) of forested land area derived with the field inventory (NFI) and post-stratification (PS), and the relative efficiency (RE) of PS in the test areas of different sizes in sampling region 1

\begin{tabular}{|c|c|c|c|c|c|c|c|}
\hline \multirow[t]{2}{*}{ Size $\left(\mathrm{km}^{2}\right)$} & \multirow[t]{2}{*}{ Method } & \multicolumn{3}{|c|}{$\mathrm{SE}(\%)$} & \multicolumn{3}{|l|}{ RE } \\
\hline & & Mean & Min & Max & Mean & Min & Max \\
\hline \multirow[t]{2}{*}{576} & NFI & 7.81 & 1.95 & 16.16 & & & \\
\hline & PS & 4.43 & 1.62 & 10.87 & 3.42 & 0.72 & 9.78 \\
\hline \multirow[t]{2}{*}{1152} & NFI & 5.52 & 1.68 & 9.29 & & & \\
\hline & PS & 2.91 & 1.48 & 5.19 & 3.75 & 1.31 & 8.05 \\
\hline \multirow[t]{2}{*}{2304} & NFI & 3.91 & 2.08 & 5.78 & & & \\
\hline & PS & 2.02 & 1.49 & 2.99 & 3.69 & 1.92 & 6.35 \\
\hline \multirow[t]{2}{*}{4608} & NFI & 2.74 & 1.50 & 3.80 & & & \\
\hline & PS & 1.39 & 1.08 & 1.69 & 3.78 & 1.93 & 5.67 \\
\hline \multirow[t]{2}{*}{9216} & NFI & 1.96 & 1.11 & 2.47 & & & \\
\hline & PS & 0.98 & 0.76 & 1.18 & 3.86 & 2.18 & 5.00 \\
\hline
\end{tabular}

two different time points; an example of a readily usable product is Finnish Corine Land Cover changes 2006-2012 (Törmä et al. 2011). The changes due to growth and thinning would still be missing. Another, more laborious alternative would be to update the old NFI plots for the changes and use them and new RS material to produce an independent, but more up-todate stratification. The possible improvements of such approaches remain to be studied later.

On the other hand, by using the old, published MS-NFI volume maps, we avoid many other problems in more recent satellite images, such as missing data due to clouds. In the published MS-NFI 2007 maps, there was only a small area of missing data due to clouds, which was mainly water. The missing data may have slightly affected the results of the Pohjanmaa province. In MS-NFI, the relatively good

Table 8 Statistics of the relative estimation errors (SE) of forested land area derived with the field inventory (NFI) and post-stratification (PS), and the relative efficiency (RE) of PS in the test areas of different sizes in sampling region 2

\begin{tabular}{|c|c|c|c|c|c|c|c|}
\hline \multirow[t]{2}{*}{ Size $\left(\mathrm{km}^{2}\right)$} & \multirow[t]{2}{*}{ Method } & \multicolumn{3}{|c|}{ SE $(\%)$} & \multicolumn{3}{|l|}{$\mathrm{RE}$} \\
\hline & & Mean & Min & Max & Mean & Min & Max \\
\hline \multirow[t]{2}{*}{784} & NFI & 6.37 & 2.16 & 13.94 & & & \\
\hline & PS & 3.76 & 1.75 & 6.29 & 3.12 & 0.45 & 13.69 \\
\hline \multirow[t]{2}{*}{1568} & NFI & 4.51 & 1.85 & 9.28 & & & \\
\hline & PS & 2.47 & 1.35 & 4.09 & 3.47 & 0.89 & 10.72 \\
\hline \multirow[t]{2}{*}{3136} & NFI & 3.18 & 1.46 & 6.15 & & & \\
\hline & PS & 1.67 & 1.08 & 2.46 & 3.55 & 1.59 & 6.50 \\
\hline \multirow[t]{2}{*}{6272} & NFI & 2.23 & 1.39 & 3.48 & & & \\
\hline & PS & 1.16 & 0.87 & 1.62 & 3.52 & 2.00 & 5.78 \\
\hline \multirow[t]{2}{*}{12,544} & NFI & 1.58 & 1.10 & 2.46 & & & \\
\hline & PS & 0.81 & 0.66 & 1.07 & 3.62 & 2.51 & 5.21 \\
\hline
\end{tabular}

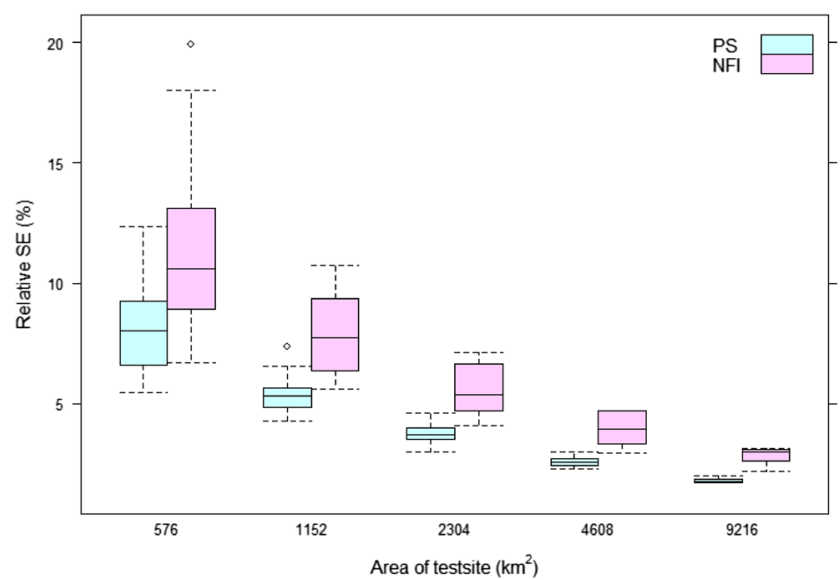

Fig. 7 Relative standard errors (SE) for total volume estimates on forested land on the test areas of different sizes, derived with poststratification (PS) and NFI sample plots only (NFI) in sampling region 1 (Southern Finland)

coverage can be obtained because the maps are based on satellite images from one or more years. Generally, cloud gaps are patched with older images or images with poorer quality. In addition, satellite images have between-image differences, which affect the MA and PS results. In the MS-NFI forest resources maps, these differences have been somewhat reduced by the used $k \mathrm{nn}$ approach, where plots only within the image area are utilized as reference data (Tomppo et al. 2008, 2012): While the images differ, the estimated forest characteristics have the properties of the underlying forests. In our case, the off-the-shelf forest resource map makes PS fully operational from the start. MS-NFI maps are produced every other year for the whole country except Åland islands and Northern Lapland, which are covered less frequently (Metla 2013; Mäkisara et al. 2016). The Finnish NFI in turn is a continuous inventory where one round is completed in every 5 years. The

Table 9 Statistics of the relative estimation errors (SE) of total volume derived with the field inventory (NFI) and post-stratification (PS), and the relative efficiency (RE) of PS in the test areas of different sizes in sampling region 1

\begin{tabular}{|c|c|c|c|c|c|c|c|}
\hline \multirow[t]{2}{*}{ Size $\left(\mathrm{km}^{2}\right)$} & \multirow[t]{2}{*}{ Method } & \multicolumn{3}{|c|}{ SE $(\%)$} & \multicolumn{3}{|l|}{$\mathrm{RE}$} \\
\hline & & Mean & Min & Max & Mean & Min & Max \\
\hline \multirow[t]{2}{*}{576} & NFI & 11.25 & 6.72 & 19.89 & & & \\
\hline & PS & 8.13 & 5.49 & 12.34 & 2.09 & 0.76 & 4.36 \\
\hline \multirow[t]{2}{*}{1152} & NFI & 7.89 & 5.62 & 10.75 & & & \\
\hline & PS & 5.38 & 4.28 & 7.37 & 2.27 & 1.09 & 4.12 \\
\hline \multirow[t]{2}{*}{2304} & NFI & 5.60 & 4.11 & 7.13 & & & \\
\hline & PS & 3.75 & 3.01 & 4.61 & 2.30 & 1.30 & 3.60 \\
\hline \multirow[t]{2}{*}{4608} & NFI & 3.94 & 2.93 & 4.74 & & & \\
\hline & PS & 2.60 & 2.27 & 3.01 & 2.36 & 1.48 & 3.40 \\
\hline \multirow[t]{2}{*}{9216} & NFI & 2.79 & 2.20 & 3.14 & & & \\
\hline & PS & 1.82 & 1.72 & 1.98 & 2.41 & 1.64 & 3.26 \\
\hline
\end{tabular}




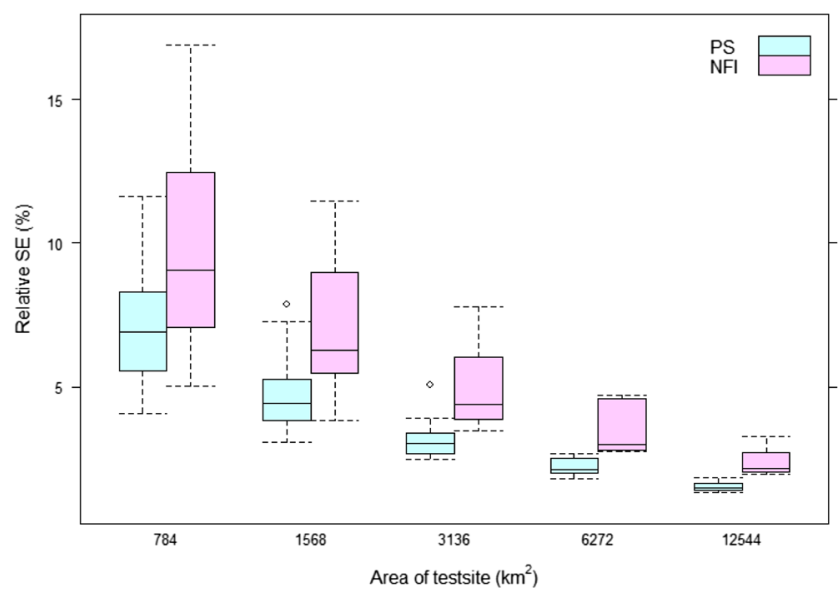

Fig. 8 Relative standard errors (SE) for total volume estimates on forested land on the test areas of different sizes, derived with poststratification (PS) and NFI sample plots only (NFI) in sampling region 2 (Central Finland)

availability of MS-NFI maps would not be a problem, while PS would be relying on MS-NFI maps based on the field data of the previous NFI round.

In MA approaches, it is very important that the area of forest land is accurately known to avoid biased estimates. The erroneous forest area will introduce bias if, e.g., the model predicts high volumes or biomass to areas that is not forest at all, for instance, on waterbodies. In PS, the strata sizes are needed for weighting the strata, and incorrect weights result in less accurate estimates but not biased. Although bias can be avoided, it is important to have accurate map data also in PS to obtain precise results that are comparable to the official statistics, for example, on land use areas. In the NLS map data, areas of waterbodies are regarded as being accurate, whereas areas of other land uses are underestimated (Tomppo et al. 2008). In MS-NFI, i.e., in estimating forest statistics for

Table 10 Statistics of the relative estimation errors (SE, \%) of total volume derived with the field inventory (NFI) and post-stratification (PS), and the relative efficiency (RE) of PS in the test areas of different sizes in sampling region 2

\begin{tabular}{|c|c|c|c|c|c|c|c|}
\hline \multirow[t]{2}{*}{ Size $\left(\mathrm{km}^{2}\right)$} & \multirow[t]{2}{*}{ Method } & \multicolumn{3}{|c|}{ SE $(\%)$} & \multicolumn{3}{|l|}{$\mathrm{RE}$} \\
\hline & & Mean & Min & Max & Mean & Min & Max \\
\hline \multirow[t]{2}{*}{784} & NFI & 9.80 & 5.03 & 16.88 & & & \\
\hline & PS & 7.00 & 4.07 & 11.61 & 2.27 & 0.53 & 8.74 \\
\hline \multirow[t]{2}{*}{1568} & NFI & 6.99 & 3.81 & 11.45 & & & \\
\hline & PS & 4.65 & 3.06 & 7.84 & 2.46 & 1.02 & 5.79 \\
\hline \multirow[t]{2}{*}{3136} & NFI & 4.94 & 3.47 & 7.79 & & & \\
\hline & PS & 3.19 & 2.45 & 5.07 & 2.52 & 1.24 & 6.22 \\
\hline \multirow[t]{2}{*}{6272} & NFI & 3.47 & 2.75 & 4.69 & & & \\
\hline & PS & 2.20 & 1.78 & 2.68 & 2.42 & 1.81 & 3.21 \\
\hline \multirow[t]{2}{*}{12,544} & NFI & 2.46 & 1.96 & 3.28 & & & \\
\hline & PS & 1.54 & 1.33 & 1.81 & 2.48 & 2.02 & 3.26 \\
\hline
\end{tabular}

municipalities by means of $k \mathrm{nn}$, the plot weights are corrected with a calibration method to reduce the errors due to confusion between forestry land and other land use classes in the field data and on the map (Katila et al. 2000). Also the accuracy of PS results could be improved by adjusting stratum areas according to calibrated municipality areas.

\section{Conclusion}

The main conclusion is that the utilization of an old forest resources map is a fully operational approach for nationallevel post-stratification. The efficiency improvements were surprisingly good, given that the correlations between Landsat images and forest resources are modest, and the map was several years old. PS clearly improved the precision of the forest estimates at the province level, compared to the estimates based on field plots only, for example, on average by $33 \%$ in the case of total volume. PS also enabled calculating the results accurately for markedly smaller areas than with the field plots. It is also very important that the post-stratified estimates for small areas were robust, meaning that the possibility of very poor estimates was clearly lower than with the estimates based on field plots only. The interest of using PS in small area estimation, for example, at the municipality level in Finland, is the design-based inference. This would be an advantage compared to the currently used model-based approach, MS-NFI $(k \mathrm{nn})$, which has a possibility of bias and lacks an analytical error estimator for areas of different sizes. The results of this study confirmed that with the current NFI sampling, PS could be used to estimate forest statistics accurately for large municipalities and combinations of municipalities.

In PS approach, it is critical that the strata are accurately delineated and the sample plots are assigned to correct strata. The precision of forest estimates could be further improved by using updated image material, for example, by updating regeneration cuttings to improve the correlation between the MS-NFI map data and current plot data. Because of the high errors of $k \mathrm{nn}$ predictions at the pixel level, the precision of PS estimates could be potentially improved by using segmentation, i.e., post-stratifying homogenous segments derived from $k \mathrm{nn}$ volume maps or original Landsat images. Moreover, the accuracy of PS results could be improved by adjusting stratum areas according to calibrated municipality areas, i.e., corrected for map errors in land use classes.

Acknowledgments Open access funding provided by Natural Resources Institute Finland (LUKE). We want to thank the NFI staff of the Natural Resources Institute Finland (until 1, January 2015 the Finnish Forest Research Institute) who have contributed to the NFI and MS-NFI materials applied in this study. We would also like to thank the anonymous referees for their valuable comments on the manuscript. 
Contribution of the co-authors Haakana compiled the data, conducted the analyses, and wrote most of the manuscript. Heikkinen developed the estimators, consulted on the calculations, and wrote the methods concerning the estimators. Katila provided tools for post-stratification and consulted on the post-stratification. Kangas coordinated the research, drafted the manuscript, and wrote the introduction part. Heikkinen, Katila, and Kangas commented and revised the manuscript.

Funding The study was conducted as a part of the NFI2020 project funded by the Finnish Ministry of Agriculture and Forestry.

Statement of data availability The datasets generated and analyzed during the current study are available from the corresponding author on reasonable request. Restrictions apply to the availability of NFI sample plot data because they contain sensitive locational information, and the map data which was used under license from the National Land Survey of Finland.

\section{Compliance with ethical standards}

Conflict of interest The authors declare that they have no conflict of interest.

Open Access This article is distributed under the terms of the Creative Commons Attribution 4.0 International License (http:// creativecommons.org/licenses/by/4.0/), which permits unrestricted use, distribution, and reproduction in any medium, provided you give appropriate credit to the original author(s) and the source, provide a link to the Creative Commons license, and indicate if changes were made.

Publisher's note Springer Nature remains neutral with regard to jurisdictional claims in published maps and institutional affiliations.

\section{References}

Baffetta F, Fattorini L, Franceschi S, Corona P (2009) Design-based approach to $k$-nearest neighbours technique for coupling field and remotely sensed data in forest surveys. Remote Sens Environ 113: 463-475. https://doi.org/10.1016/j.rse.2008.06.014

Barrett F, McRoberts RE, Tomppo E, Ciendala E, Waser LT (2016) A questionnaire-based review of the operational use of remotely sensed data by national inventories. Remote Sens Environ 174: 279-289. https://doi.org/10.1016/j.rse.2015.08.029

Breidt FJ, Opsomer JD (2008) Endogenous post-stratification in surveys: classification with a sample fitted model. Ann Stat 36:403-427. https://doi.org/10.1214/009053607000000703

Cassel C-M, Särndal C-E, Wretman JH (1977) Foundations of inference in survey sampling. John Wiley and Sons, New York, p 192

Cochran WG (1977) Sampling techniques. John Wiley and Sons, New York, $\mathrm{p} 428$

Dahlke M, Breidt FJ, Opsomer JD, Van Keilegom I (2013) Nonparametric endogenous post-stratification estimation. Stat Sin 23:189-211. https://doi.org/10.5705/ss.2011.272

Dalenius T, Hodges JL Jr (1959) Minimum variance stratification. J Am Stat Assoc 54:88-101. https://doi.org/10.1080/01621459.1959.10501501

Ene LT, Gobakken T, Andersen H-E, Næsset E, Cook BD, Morton DC, Babcock C, Nelson R (2018) Large-area hybrid estimation of aboveground biomass in interior Alaska using airborne laser scanning data. Remote Sens Environ 204:741-755. https://doi.org/10.1016/j.rse.2017.09.027

FAO (2012) FRA 2015 Terms and Definitions. Forest resources Assessment Working Paper 180, 31. http://www.fao.org/docrep/ 017/ap862e/ap862e00.pdf. Accessed 2 November 2017
Fridman J, Holm S, Nilsson M, Nilsson P, Ringvall AH, Ståhl G (2014) Adapting National Forest Inventories to changing requirementsthe case of the Swedish National Forest Inventory at the turn of the 20th century. Silva Fenn 48(3 1095):29. https://doi.org/10.14214/sf. 1095

Grafström A, Zhao X, Nylander M, Petersson H (2017) A new sampling strategy for forest inventories applied to the temporary clusters of the Swedish national forest inventory. Can J For Res 47:1161-1167. https://doi.org/10.1139/cjfr-2017-0095

Gregoire TG, Ståhl G, Næsset E, Gobakken T, Nelson R, Holm S (2011) Model-assisted estimation of biomass in a lidar sample survey in Hedmark county. Norway Can J For Res 41:83-95. https://doi.org/ 10.1139/X10-195

Holt D, Smith TMF (1979) Post stratification. J Royal Statist Soc Series A (General) 142(1):33-46. https://doi.org/10.2307/2344652

Kangas A, Astrup R, Breidenbach J, Fridman J, Gobakken T, Korhonen KT, Maltamo M, Nilsson M, Nord-Larsen T, Næsset E, Olsson H (2018) Remote sensing and forest inventories in Nordic countriesroadmap for the future. Scand J For Res 33:397-412. https://doi.org/ 10.1080/02827581.2017.1416666

Kangas A, Myllymäki M, Gobakken T, Næsset E (2016) Model-assisted forest inventory with parametric, semi-parametric, and nonparametric models. Can J For Res 46:855-868. https://doi.org/10. $1139 / \mathrm{cjfr}-2015-0504$

Katila M (2006) Empirical errors of small area estimates from the multisource National Forest Inventory in Eastern Finland. Silva Fennica 40:729-742 http://www.metla.fi/silvafennica/full/sf40/sf404729. pdf. Accessed 2 November 2017

Katila M, Heikkinen J, Tomppo E (2000) Calibration of small-area estimates for map errors in multisource forest inventory. Can J For Res 30:1329-1339. https://doi.org/10.1139/x99-234

Katila M, Tomppo E (2001) Selecting estimation parameters for the Finnish multisource National Forest Inventory. Remote Sens Environ 76:16-32. https://doi.org/10.1016/S0034-4257(00)00188-7

Katila M, Tomppo E (2002) Stratification by ancillary data in multisource forest inventories employing $k$-nearest-neighbour estimation. Can J For Res 32:1548-1561. https://doi.org/10.1139/x02-047

Korhonen KT, Ihalainen A, Ahola A, Heikkinen J, Henttonen HM, Hotanen J-P, Nevalainen S, Pitkänen J, Strandström M, Viiri H (2017) Suomen metsät 2009-2013 ja niiden kehitys 1921-2013. Luonnonvara- ja biotalouden tutkimus 59/2017. Luonnonvarakeskus, Helsinki. 86 p. http://urn.fi/URN:ISBN:978952-326-467-0. Accessed 14 December 2017

Magnussen S (2013) An assessment of three variance estimators for the knearest neighbour technique. Silva Fenn 47(1 925):19. https://doi. org/10.14214/sf.925

Magnussen S, Andersen H-E, Mundhenk P (2015) A second look at endogenous poststratification. For Sci 61:624-634. https://doi.org/ 10.5849 /forsci. $14-183$

Magnussen S, Frazer G, Penner M (2016) Alternative mean-squared error estimators for synthetic estimators of domain means. J Appl Stat 43: 2550-2573. https://doi.org/10.1080/02664763.2016.1142942

Magnussen S, Mandallaz D, Breidenbach J, Lanz A, Ginzler C (2014) National forest inventories in the service of small area estimation of stem volume. Can J For Res 44:1079-1090. https://doi.org/10.1139/ cjfr-2013-0448

Mäkisara K, Katila M, Peräsaari J, Tomppo E (2016) The Multi-Source National Forest Inventory of Finland-methods and results 2013. Natural resources and bioeconomy studies 10/2016. Natural Resources Institute Finland, Helsinki. 215 p. http://urn.fi/URN: ISBN:978-952-326-186-0. Accessed 26 October 2018

Matérn B (1960) Spatial variation. Meddelanden från Statens Skogsforskningsinstitut $49.5,144$ p. also appeared as number 36 of lecture notes in statistics. Springer-Verlag, New York, p 1986

McRoberts RE (2010) Probability- and model-based approaches to inference for proportion forest using satellite imagery as ancillary data. 
Remote Sens Environ 114:1017-1025. https://doi.org/10.1016/j.rse. 2009.12.013

McRoberts RE, Chen Q, Walters BF (2017) Multivariate inference for forest inventories using auxiliary airborne laser scanning data. For Ecol Manag 401:295-303. https://doi.org/10.1016/j.foreco.2017.07. 017

McRoberts RE, Gobakken T, Næsset E (2012) Post-stratified estimation of forest area and growing stock volume using lidar-based stratifications. Remote Sens Environ 125:157-166. https://doi.org/10. 1016/j.rse.2012.07.002

McRoberts RE, Holden GR, Nelson MD, Liknes GC, Gormanson DD (2006) Using satellite imagery as ancillary data for increasing the precision of estimates for the Forest Inventory and Analysis program of the USDA Forest Service. Can J For Res 36:2968-2980. https:// doi.org/10.1139/X05-222

McRoberts RE, Liknes GC, Domke GM (2014) Using a remote sensingbased, percent tree cover map to enhance forest inventory estimation. For Ecol Manag 331:12-18. https://doi.org/10.1016/j.foreco. 2014.07.025

McRoberts RE, Nelson MD, Wendt DG (2002) Stratified estimation of forest area using satellite imagery, inventory data, and the $k$-nearest neighbors technique. Remote Sens Environ 82:457-468

Metla (2013) File service for publicly available data. http://kartta.luke.fi/ index-en.html. Accessed 26 October 2018

Myllymäki M, Gobakken T, Næsset E, Kangas A (2017) The efficiency of post-stratification compared to model-assisted estimation. Can J For Res 47:515-526. https://doi.org/10.1139/cjfr-2016-0383

Nilsson M, Folving S, Kennedy P, Puumalainen J, Chirici G, Corona P, Marchetti M, Olsson H, Ricotta C, Ringvall A, Ståhl G, Tomppo E (2003) Combining remote sensing and field data for deriving unbiased estimates of forest parameters over larger regions. In: Corona $\mathrm{P}$, Köhl M, Marchetti M (eds.) Advances in forest inventory for sustainable forest management and biodiversity monitoring. Forestry Sciences, vol 76, Springer, Dordrecht, pp 19-32. doi:https://doi. org/10.1007/978-94-017-0649-0_2

Nilsson M, Holm S, Reese H, Wallerman J, Engberg J (2005) Improved forest statistics from the Swedish National Forest Inventory by combining field data and optical satellite data using post-stratification. In: Proceedings of ForestSat 2005 in Borås May 31-June 3. Olsson H (ed.), National Board of Forestry May 2005, Skogsstyrelsens förlag, Jönköping, pp 22-26

Opsomer JD, Breidt FJ, Moisen GG, Kauermann G (2007) Modelassisted estimation of forest resources with generalized additive models. J Am Stat Assoc 102:400-409. https://doi.org/10.1198/ 016214506000001491

Räty M, Heikkinen J, Kangas A (2018) Assessment of sampling strategies utilizing auxiliary information in large-scale forest inventory. Can J For Res 48:1-9. https://doi.org/10.1139/cjfr-2017-0414

Saarela S, Grafström A, Ståhl G, Kangas A, Holopainen M, Tuominen S, Nordkvist K, Hyyppä J (2015a) Model-assisted estimation of growing stock volume using different combinations of LiDAR and Landsat data as auxiliary information. Remote Sens Environ 158: 431-440. https://doi.org/10.1016/j.rse.2014.11.020
Saarela S, Schnell S, Grafström A, Tuominen S, Nordkvist K, Hyyppä J, Kangas A, Ståhl G (2015b) Effects of sample size and model form on the accuracy of model-based estimators of growing stock volume. Can J For Res 45:1524-1534. https://doi.org/10.1139/cjfr2015-0077

Särndal C-E, Swensson B, Wretman J (1992) Model assisted survey sampling. Springer, New York, p 694

Ståhl G, Holm S, Gregoire TG, Gobakken T, Næsset E, Nelson R (2011) Model-based inference for biomass estimation in a LiDAR sample survey in Hedmark County. Norway Can J For Res 41:96-107. https://doi.org/10.1139/X10-161

Tipton J, Opsomer J, Moisen G (2013) Properties of endogenous poststratified estimation using remote sensing data. Remote Sens Environ 139:130-137. https://doi.org/10.1016/j.rse.2013.07.035

Tomppo E (1996) Multi-source National Forest Inventory of Finland. In: Päivinen R, Vanclay J, Miina S (eds.) New Thrusts in Forest Inventory. Proceedings of the subject group S4.02-00 'Forest Resource Inventory and Monitoring' and subject group S4.12-00 'Remote Sensing Technology', vol. 1. IUFRO XX World Congress, 6-12 Aug. 1995, Tampere, Finland. European Forest Institute, Joensuu. p. $27-41$

Tomppo E, Gschwantner T, Lawrence M, McRoberts RE (2010) (Eds) National Forest Inventories, pathways for common reporting. Springer, Dordrecht, p 612. https://doi.org/10.1007/978-90-4813233-1

Tomppo E, Haakana M, Katila M, Peräsaari J (2008) Multi-source national forest inventory - methods and applications. Managing Forest Ecosystems 18. Springer. 373. doi:https://doi.org/10.1007/978-14020-8713-4

Tomppo E, Halme M (2004) Using coarse scale forest variables as ancillary information and weighting of variables in k-NN estimation: a genetic algorithm approach. Remote Sens Environ 92:1-20. https:// doi.org/10.1016/j.rse.2004.04.003

Tomppo E, Heikkinen J, Henttonen HM, Ihalainen A, Katila M, Mäkelä $\mathrm{H}$, Tuomainen T, Vainikainen N (2011) Designing and conducting a forest inventory - case: 9th National Forest Inventory of Finland. Managing Forest Ecosystems 21, springer. 270. doi:https://doi.org/ 10.1007/978-94-007-1652-0

Tomppo E, Katila M, Mäkisara K, Peräsaari J (2012) The Multi-source National Forest Inventory of Finland - methods and results 2007. Working Papers of the Finnish Forest Research Institute 227. 233. http://www.metla.fi/julkaisut/workingpapers/2012/mwp227.htm. Accessed 16 November 2017

Tomppo E, Malimbwi R, Katila M, Mäkisara K, Henttonen HM, Chamuya N, Zahabu E, Otieno J (2014) A sampling design for a large area forest inventory: case Tanzania. Can J For Res 44:931948. https://doi.org/10.1139/cjfr-2013-0490

Törmä M, Härmä P, Hatunen S, Teiniranta R, Kallio M, Järvenpää E (2011) Change detection for Finnish CORINE land cover classification. Proc. SPIE 8181, Earth Resources and Environmental Remote Sensing/GIS Applications II, 81810Q. doi: https://doi.org/10.1117/ 12.898069 